\title{
Wheat genetic resources as a raw material for healthy food
}

Abugaliyeva A.I. ${ }^{*}$, Savin T.V. ${ }^{2}$

${ }^{1}$ Kazakh Research Institute of Agriculture and Plant Growing, Almalybak, Kazakhstan

${ }^{2}$ Karabalyk Agricultural Experimental Station, Kostanay region, Kazakhstan

*e-mail:kiz_abugalieva@mail.ru

23 introgressive winter investigated and 27 spring wheat forms for (1) macro- and microelement content, especially $\mathrm{Zn}, \mathrm{Fe}, \mathrm{Cd}$; (2) protein and fractions content, including $\alpha_{6}$ components; (3) content of amylose, $\beta$-glucan, arabynoxylanc; (4) fatty acid composition. The source of high $\mathrm{N}, \mathrm{Mg}, \mathrm{Mn}$ and $\mathrm{Fe}, \mathrm{Zn}$ contents can be considered T. kiharae; of $\mathrm{N}, \mathrm{P}, \mathrm{S}-T$. militinae; $\mathrm{Mn}, \mathrm{Fe}, \mathrm{Zn}-T$. petropavloskyi; of $\mathrm{K}$ and $\mathrm{Zn}-$ T. compactum. The protein content in the grain of various species was formed due to the predominance of different protein fractions: globulin in grain of Ae. triaristata (40.6 \% to the total) and T. militinae $(35.7 \%)$; due to gliadin in $T$. dicoccoides (38.9\%), T. dicoccum $(34.5 \%)$ and T. timopheevi $(33.7 \%)$. By the ratio of protein fractions in the $70 \%$ ground flour, winter introgressive forms were characterized by the predominance of albumin + globulin fraction from 40.4-44.0 \%; 1721-9 and 2041-13 to $55.3 \%$ (Bezostaya $1 \times$ Ae. triaristata $) \times$ Karlygash. The maximum content of $\beta$-glucan is characteristic of Aegilops (Ae. triaristata and Ae. cylindrica), then T. dicoccoides and T. macha. Consistently high content of $\beta$-glucan was observed in T. shaerococcum and $T$. timopheevi, content of arabinoxylane for Zhetysu $\times T$. militinae. Wild relatives were characterized by an amylose content in the range of: T. timopheevi $(31.5 \%)>$ $>$ T. dicoccoides $(29.3 \%)$; T. macha $(28.1 \%)$; T. persicum $(27.7 \%)>$ T. spelta $(27.0 \%)>$ $>$ T. militinae, T. spharacoccum (26.4\%). Amylose content in Aegilops ranged from $9.6 \%$ (Ae. triaristata) to $13.3 \%$ (Ae. triuncialis). Rising interest in natural and organic products led to the reopening of ancient wheat as a source of grain for healthy nutrition. Several wheat species are used and further adapted to cultivation in industrial scale, e.g., Khorasan, T. spelta, T. compactum. However, these wheat forms have drawbacks, which hinder their widespread use. In this regard, interspecific and intergeneric wheat hybrids are convenient and promising objects that ideally combine nutrient and technological properties with agronomic suitability. 